\title{
Interaction of pollination and number of leaves in the tomato
}

\section{K. VERKERK}

Laboratorium voor Tuinbouwplantenteelt, Landbouwhogeschool, Wageningen, Netherlands

\section{CONTENTS}

\section{Summary}

1. Introduction

2. Description of experiment

3. Results
3.1. Fruit yield
3.2. Seed yield

4. Discussion

References

\section{Summary}

The effects of an unusually intensive pollination, obtained with an electric pollinator, and of a number of leaves larger than usual, obtained either by topping the plant or by removal of young flower clusters, were studied in two tomato cultivars, 'Ailsa Craig' and 'Tuckqueen'.

The result of extra pollination is an earlier and, in most cases, higher yield. Extra leaves also increase the yield, especially of the cluster nearest to them, but retard the harvest. When only a few extra leaves are present, their effect is not influenced by extra pollination, but when the number of extra leaves is large, their effect is considerable only in connection with extra intensive pollination.

After extra pollination the mean fruit weight is higher. The number of fruits is usually smaller, but when extra leaves are present this difference may disappear or even change into its opposite.

The number of seeds in a fruit of $100 \mathrm{~g}$ increases strongly with extra heavy pollination, more so in higher clusters than in lower ones and less when the plants have more leaves.

\section{Introduction}

The yield of the tomato plant consists of the fruit. Two important prerequisites of normal fruit growth are pollination of the flower, and a steady stream of assimilates from the leaves. The present study deals with the effect of the intensity of pollination, as well as with the effect of the number of leaves on earliness and total yield. Both factors are treated together as they were found to interact.

The literature on pollination was reviewed in a previous paper (VERKERK, 1957). It

1 Also published as: Publication 237, Laboratorium voor Tuinbouwplantenteelt, Landbouwhogeschool, Wageningen, The Netherlands.

Received for publication 19th December, 1962. 
was shown that there is a positive correlation between size of the fruit and number of seeds. The greater the number of seeds, the lower the fruit weight per seed, however. The more seeds already developing on a plant, the smaller the fruit weight which newly developing seeds will contribute to the fruits containing them.

In experiments on the effect of leaf number, two methods have been used. In the first, the number of clusters was kept constant, but the number of leaves was varied; in the second, the number of leaves was increased together with the number of clusters.

Hemphil a and MURNeEK (1948) left two axil shoots under each cluster, taking the tip of these shoots away after the second leaf. In comparison to the controls (axil shoots removed) this gave more and heavier fruits, resulting in an increase in yield by about one third. Nothing is said about earliness, unfortunately. KERR (1949/50) did a similar experiment with 39 cultivars, but did not find an increase in yield. LAMM (1956) left two axil shoots with one leaf each to a cluster and obtained a later harvest. Borowicz-Kepxowa (1937) found that fruits of the third to fifth cluster were heavier if higher clusters, but not the leaves, were removed.

The second method was followed by THOMPSON (1934), who compared plants with one stem to plants in which the lateral shoots had not been removed. The former gave a higher yield in the first 15-19 days of picking, but the total yield was lower Rozgon (1935) also reports that pruning results in a lower, but earlier yield. Woods (1938) states that earliness is increased by strong pruning, and late pruning leads to a higher yield. HAWTHORN (1940) gives relative yields for plants with one stem, two stems, and unpruned. After two weeks of picking the ratio was $34-29-11$, after five weeks $160-190-230$. These results, to which can be added similar ones obtained by BorowiCz-KepKowa (1937), Homès et al. (1950) and Cooper (1960) all lead to the conclusion that early pruning stimulates fruit growth in general, but at the cost of vegetative growth, so that the total yield will be smaller than after late or less severe pruning.

\section{Description of experiment}

The experiment was carried out during summer in an unheated greenhouse. The two tomato cultivars used, Ailsa Craig and Tuckqueen, give about the same yield, but the former has many relatively small fruits, while the latter forms less, but larger fruits.

The extra heavy pollination was carried out by means of an electric vibrator (VERKERK, 1957; VERKERK and WellensieK, 1950; Wellensiek, 1948). In the eye of a needle the flower is shaken vigorously and consequently pollinated intensively. Half of the plants were pollinated in this way, three times a week, at the end of the morning (vibrated $=+v)$. In the controls $(-v)$ pollination was left to nature.

The small lateral shoots were pinched out once a week. In addition the following ways of pruning were used:

$a$. topping above the second leaf after the third cluster, resulting in three clusters,

$b$. topping above the second leaf after the fifth cluster, pinching out the fourth and fifth cluster in a young stage, resulting in three clusters,

c. topping the plants above the second leaf after the fifth cluster, resulting in five clusters.

Treatment $c$, the check, is a method used in practice and the effects of treatments 
$a$ and $b$ will be compared especially with this practical method $c$. The number of leaves per cluster is smallest in treatment $c$, greater in $a$ and largest in $b$. Normally after every three leaves a cluster is formed. Thus the number of leaves for the first three clusters is for treatment $c: 3 \times 3=9$, for treatment $a: 3 \times 3+2$ $=11$, i.e. $12 \%$ more, and for treatment $b: 3 \times 5+2=17$, i.e. $89 \%$ more than for $c$.

The total experiment consisted of six blocks. Within each block half of the plants was vibrated $(+v)$, the other half was not $(-v)$. Within these halves one third was submitted to treatment $a$, another to $b$ and the last third to $c$. Within each of these there was one row of five Ailsa Craig plants and one row of five Tuckqueen plants. The total experiment consisted of $6 \times 2 \times 3 \times 2 \times 5=360$ plants. Distances between the rows were $80 \mathrm{~cm}$, between the plants within the rows $45 \mathrm{~cm}$.

The fruits were harvested, counted and weighed at regular intervals three times a week.

\section{Results}

\subsection{Fruit yield}

The results will be presented as the mean of 30 plants, belonging to the same treatment. Only the first three clusters are comparable. TABLE 1 shows the subtotalised fruit yield of these three clusters. Varietal differences in yield are small, although Ailsa Craig, being a small fruited cultivar, tends to be somewhat earlier than Tuckqueen.

TABLE 1. Yield of the first three clusters together in $100 \mathrm{~g}$ up to mentioned date, with $(+v)$ or without $(-v)$ extra heavy pollination; treatments $c, a, b$ : see text

\begin{tabular}{|c|c|c|c|c|c|c|c|c|c|c|c|c|c|}
\hline \multirow[t]{3}{*}{ Date } & \multirow{3}{*}{$\mathbf{T}:$} & \multicolumn{6}{|c|}{ Ailsa Craig } & \multicolumn{6}{|c|}{ Tuckqueen } \\
\hline & & \multicolumn{2}{|c|}{$c$} & \multicolumn{2}{|c|}{$a$} & \multicolumn{2}{|c|}{$b$} & \multicolumn{2}{|c|}{$c$} & \multicolumn{2}{|c|}{$a$} & \multicolumn{2}{|c|}{$b$} \\
\hline & & $-\mathbf{v}$ & $+v$ & $-v$ & $+v$ & $-\mathbf{v}$ & $+v$ & $-\mathbf{v}$ & $+v$ & $-v$ & $+v$ & $-v$ & $+\mathrm{v}$ \\
\hline $\begin{array}{c}26 / 7 \\
9 / 8 \\
23 / 8 \\
15 / 10\end{array}$ & $\ldots$ & $\begin{array}{l}2,9 \\
17 \\
22 \\
26\end{array}$ & $\begin{array}{l}6,8 \\
22 \\
26 \\
30\end{array}$ & $\begin{array}{l}2,6 \\
17 \\
23 \\
29\end{array}$ & $\begin{array}{l}6,4 \\
24 \\
29 \\
35\end{array}$ & $\begin{array}{c}2,0 \\
19 \\
26 \\
31\end{array}$ & $\begin{array}{l}5,8 \\
26 \\
31 \\
39\end{array}$ & $\begin{array}{l}2,6 \\
18 \\
23 \\
28\end{array}$ & $\begin{array}{c}5,7 \\
23 \\
27 \\
32\end{array}$ & $\begin{array}{l}2,4 \\
19 \\
26 \\
32\end{array}$ & $\begin{array}{c}5,4 \\
23 \\
29 \\
36\end{array}$ & $\begin{array}{c}2,2 \\
17 \\
25 \\
33\end{array}$ & $\begin{array}{c}4,8 \\
24 \\
30 \\
40\end{array}$ \\
\hline
\end{tabular}

$\mathbf{T}=$ treatment.

The effect of the heavy pollination is very pronounced: $+v$ results in a much earlier and also higher total yield (GIBSON, 1959; HAN and VERKERK, 1953; KERR and KRIBS, 1955; VERKERK, 1957; VERKERK and WELLENSIEK, 1950).

To describe the effect of treatments $a$ and $b$ in comparison to $c$ the data of TABLE 1 are rearranged in FIG. 1. Here the treatments $a$ and $b$ are given as percentages of the comparable treatments $c$. Differences less than $10 \%$ are not important. On July 26, the first given date, the harvest is highest in $c$ and lowest in $b$ in both cultivars and in $-v$ and $+v$. The more leaves per cluster, the later the beginning of the harvest. On August 9 the differences are not very pronounced. Up till August 23 the yield of $a$ and $b$ is larger than that of $c$. The total yield on October 15 shows just the opposite order as in the beginning: the more leaves per cluster, the higher total yield. 
Fig. 1. Yield of treatments $a$ and $b$ in percentages of the control $c$ up to mentioned date in the two cultivars and without $(-v)$ or with $(+v)$ extra heavy pollination
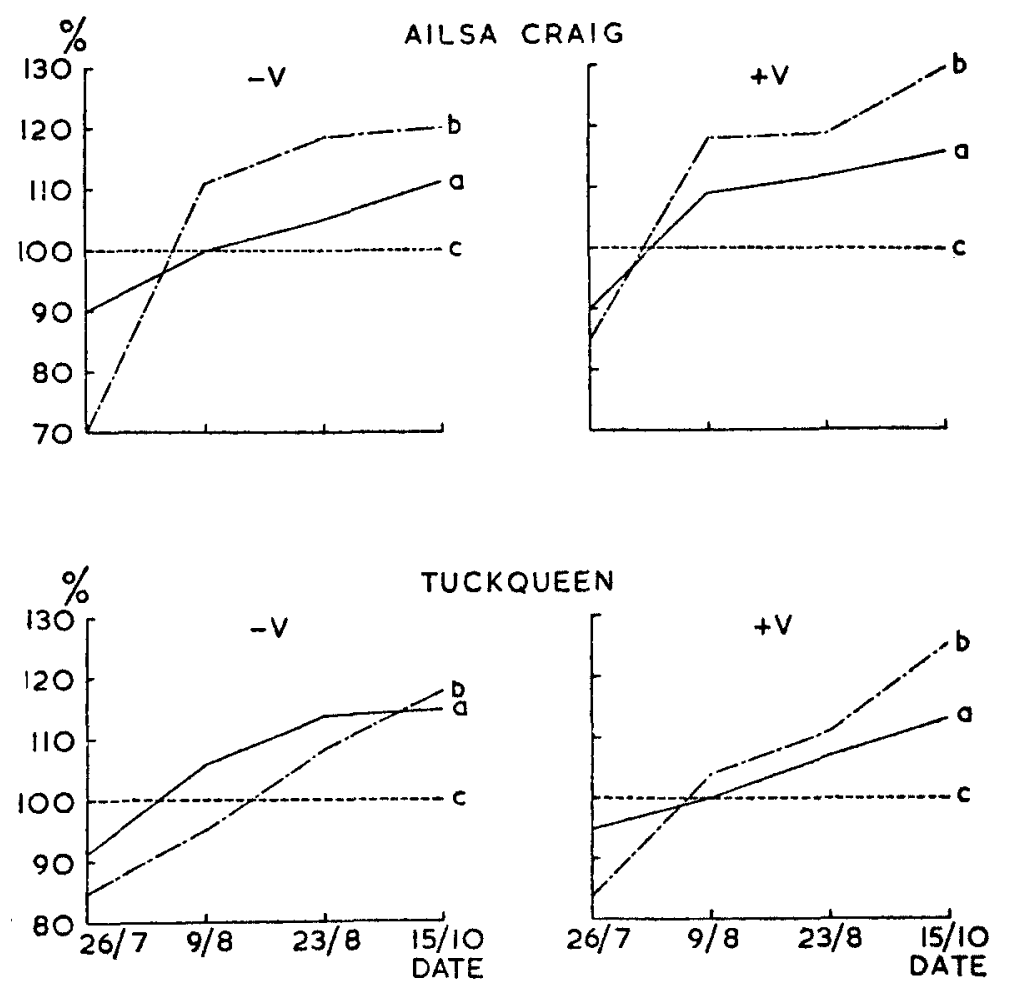

The yield in treatment $a$ is about $12 \%$ more than in treatment $c$, which is exactly the same as the $12 \%$ addition in leaf number; in treatment $b$ the difference of about $25 \%$ is much less than the $89 \%$ of additional leaves, however.

With regard to total yield, there is an interaction of leaf number and pollination. The extra yield of treatment $a$ as compared to the control $c$ is the same in and $+\mathrm{v}$, the extra yield of $b$, however, is larger in $+v$ than in $-v$. This means that extra heavy pollination is necessary to bring out the effect of the many extra leaves on fruit yield. In $+v$ the increase of $b$ over $c$ is largest in the last part of the harvest period between August 23 and October 15 (see FIG. 1).

The cultivar Ailsa Craig reacts more to the extra leaves than the cultivar Tuckqueen. If, instead of the yield of the first three clusters, all five clusters of the control are taken into account, the yield of $c$ is larger than the yield of treatments $a$ and $b$ on all dates mentioned in TABLE 1, except on August 9. This means, that althoug: the first three clusters of treatments $a$ and $b$ yield more than those of the control, the practical method is still the best because it is not only earlier, but also gives a higher total yield.

The yield is the multiplication of mean fruit weight and number of fruits. These items are given in TABLE 2. Varietal differences are very pronounced.

The effect of heavy pollination $(+v)$ on mean fruit weight is clear. In all cases $+v$ has a much larger fruit than the $-v$ treatment. 
Table 2. Mean fruit weight in grammes and number of fruits on the first three clusters together

\begin{tabular}{|c|c|c|c|c|c|c|c|c|c|c|c|c|}
\hline \multirow[t]{3}{*}{ Character } & \multicolumn{6}{|c|}{ Ailsa Craig } & \multicolumn{6}{|c|}{ Tuckqueen } \\
\hline & \multicolumn{2}{|c|}{$c$} & \multicolumn{2}{|c|}{$a$} & \multicolumn{2}{|c|}{$b$} & \multicolumn{2}{|c|}{$c$} & \multicolumn{2}{|c|}{$a$} & \multicolumn{2}{|c|}{$b$} \\
\hline & $-v$ & $+v$ & $-v$ & $+v$ & $-v$ & $+v$ & $-v$ & $+v$ & $-v$ & $+v$ & $-v$ & $+v$ \\
\hline $\begin{array}{l}\text { Fruit weight } \\
\text { Fruit weight }\end{array}$ & $\begin{array}{l}63 \\
41\end{array}$ & $\begin{array}{l}83 \\
36\end{array}$ & $\begin{array}{l}74 \\
39\end{array}$ & $\begin{array}{l}85 \\
41\end{array}$ & $\begin{array}{l}72 \\
43\end{array}$ & $\begin{array}{l}91 \\
43\end{array}$ & $\begin{array}{r}100 \\
28\end{array}$ & $\begin{array}{r}114 \\
28\end{array}$ & $\begin{array}{r}107 \\
30\end{array}$ & $\begin{array}{r}129 \\
28\end{array}$ & $\begin{array}{r}106 \\
31\end{array}$ & $\begin{array}{r}133 \\
30\end{array}$ \\
\hline
\end{tabular}

$T=$ treatment

Extra leaves (from $c$ to $a$ ) give heavier fruits. More extra leaves (from $a$ to $b$ ) give still heavier fruits, but only with a heavy pollination. The effect of treatments $c$, $a$ and $b$ on fruit number is not pronounced, although there exists a tendency for more fruits when more leaves are present. The conclusion is, that the increase in yield of the three clusters, caused by extra leaves, is mainly the result of an effect on fruit size.

As the first three clusters have a different position to the extra leaves, not all three clusters may react to the extra leaves in the same way. To get information about this all three clusters are studied separately. TABLE 3 shows the effect of heavy pollination on yield in relation to time, independent of cultivars and treatments. The heavy pollination results in an earlier yield in all clusters, while only cluster two, in an unfavourable position between one and three, does not show a higher total yield.

TABle 3. Effect of heavy pollination on yield, in relation to time, expressed as $+\mathrm{v} / \mathrm{v} \times 100$ and cumulatively determined during successive pickings

\begin{tabular}{|c|c|c|c|}
\hline Date & Cluster: 1 & 2 & 3 \\
\hline $\begin{array}{c}26 / 7 \\
9 / 8 \\
23 / 8 \\
15 / 10\end{array}$ & $\begin{array}{l}221 \\
160 \\
155 \\
153\end{array}$ & $\begin{array}{l}357 \\
108 \\
102 \\
105\end{array}$ & $\begin{array}{l}-\overline{155} \\
114 \\
119\end{array}$ \\
\hline
\end{tabular}

The effects of treatments $a$ and $b$, independent of pollination, in comparison to the control $c$ are given in TABLE 4 . With regard to earliness the treatment with the smallest number of leaves $(c)$ is the best. In Tuckqueen even treatment $a$ is better than $b$. For total yield the opposite holds true : yield is higher as the number of leaves is greater. In addition, the figures show that the cluster profits more from extra leaves when it is nearer to them : the effect is relatively better on the third cluster in relation to the second and on the second in relation to the first.

Only the third cluster shows an interaction of pollination and extra leaves. TABLE 5 demonstrates this interaction. Treatment $a$ is better than $c$ in both $-v$ and $+v$, treatment $b$ is better than $a$ in $+v$ only. So here the same holds true as for the three clusters together (page 190). To find a positive effect of $b$ over $a$, a heavy pollination is needed. 
TABLE 4. Effect of treatments on early and total yield, independent of pollination (yield of control $=100$ )

\begin{tabular}{|c|c|c|c|c|c|c|c|c|}
\hline & \multirow[t]{2}{*}{ Cluster } & \multicolumn{3}{|c|}{ Ailsa Craig } & \multicolumn{3}{|c|}{ Tuckqueen } & \multirow[t]{2}{*}{ Date } \\
\hline & & $c$ & $a$ & $b$ & $c$ & $a$ & $b$ & \\
\hline Early & $\begin{array}{l}1 \\
2 \\
3\end{array}$ & $\begin{array}{l}100 \\
100 \\
100\end{array}$ & $\begin{array}{l}80 \\
65 \\
94\end{array}$ & $\begin{array}{r}80 \\
65 \\
103\end{array}$ & $\begin{array}{l}100 \\
100 \\
100\end{array}$ & $\begin{array}{l}96 \\
71 \\
85\end{array}$ & $\begin{array}{l}85 \\
41 \\
69\end{array}$ & $\begin{array}{r}19 / 7 \\
26 / 7 \\
2 / 8\end{array}$ \\
\hline Total & $\begin{array}{l}1 \\
2 \\
3\end{array}$ & $\begin{array}{l}100 \\
100 \\
100\end{array}$ & $\begin{array}{l}107 \\
104 \\
133\end{array}$ & $\begin{array}{l}112 \\
123 \\
142\end{array}$ & $\begin{array}{l}100 \\
100 \\
100\end{array}$ & $\begin{array}{l}105 \\
117 \\
120\end{array}$ & $\begin{array}{l}107 \\
122 \\
133\end{array}$ & $\begin{array}{l}15 / 10 \\
15 / 10 \\
15 / 10\end{array}$ \\
\hline
\end{tabular}

$\mathrm{T}=$ treatment.

TABle 5. Effect of treatments on total yield of the third cluster (control $=100$ )

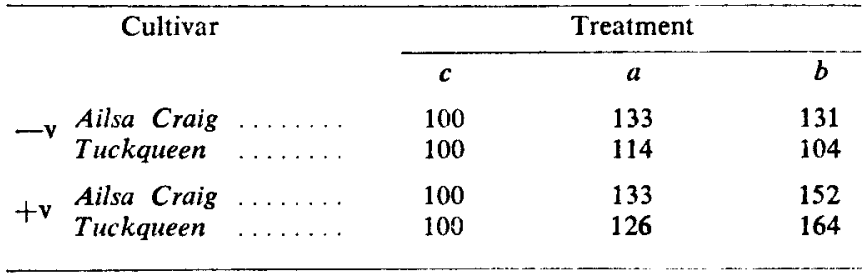

Mean fruit weight and number of fruits of the third cluster are given in FIG. 2. Again the varietal differences are very pronounced. The effect of extra pollination on mean fruit weight is also obvious. The more leaves, the larger the fruits, both in $-v$ and $+v$. The number of fruits shows a different trend. In most cases this number decreases after heavy pollination, in Ailsa Craig not in $a$ and $b$, however, and in Tuckqueen not in $b$. In the last case the number of fruits even increases after heavy pollination.

TABLE 5 shows the effect of the treatments on total yield. TABLE 6 is set up to show whether the higher yield is the result of heavier fruits, more fruits or both.

Without extra pollination ( $-v)$ the rise in yield from $c$ to $a$, as a result of extra leaf number of $12 \%$, is caused by both more and heavier fruits. From treatment $a$ to $b$ there was no rise in yield in the cultivar Ailsa Craig. In Tuckqueen the mean fruit weight rose a little, however, the number of fruits diminished, so that without extra pollination no positive effect was found from the extra large amount of leaves.

With extra pollination $(+v)$ the resuits are different. In the cultivar Ailsa Craig, naturally having a large number of fruits, the fruit number increased from $c$ to $a$ and the mean fruit weight from $a$ to $b$. In the cultivar Tuckqueen, naturally bearing heavy fruits, the opposite was found. The effect on the weight of the yield is nearly the same in both cultivars (TABLE 5 , $+v$ ).

\subsection{Seed yield}

From five fruits of about $100 \mathrm{~g}$ out of each treatment the number of seeds was counted. TABLE 7 gives the results and the differences between $+v$ and $-v$.

The number of seeds is larger with heavy pollination $(+v)$ than whinout $(-v)$. The columns for the differences between $+v$ and $-v$ show a larger figure in higher 
MEAN FRUIT WEIGHT IN GRAMMES

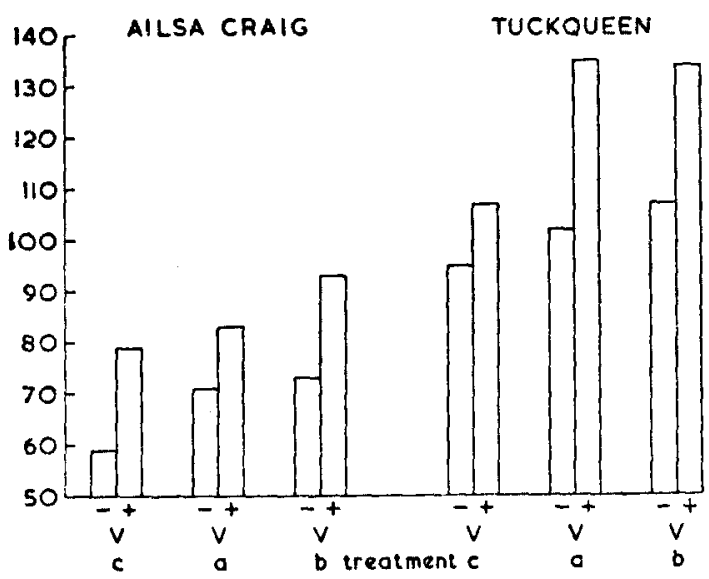

NUMBER OF FRUITS

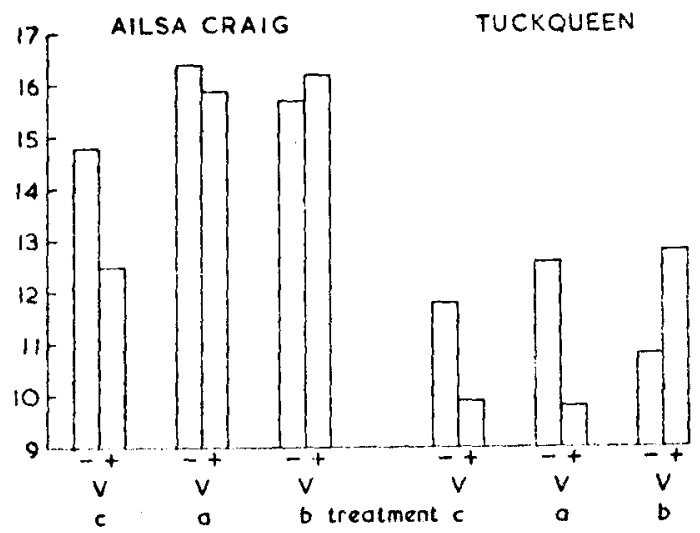

FIG. 2.

Mean fruit weight $(g)$ and number of fruits of the third cluster

TABLE 6. Differences in yield of the third cluster, expressed in mean fruit weight and number of fruits

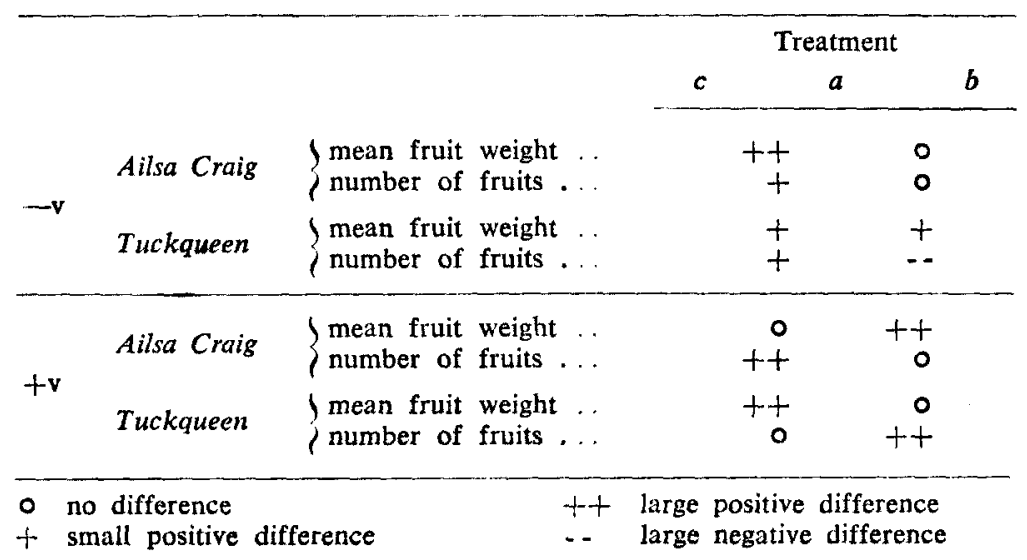


clusters which means that to get fruits of $100 \mathrm{~g}$ after extra pollination there are needed more and more extra seeds in comparison to the control. At the bottom of TABLE 7 it is shown that the more leaves, the less extra seeds are needed after heavy pollination.

TABLE 7. Seed number in fruits of $100 \mathrm{~g}$

\begin{tabular}{|c|c|c|c|c|c|c|c|c|}
\hline \multirow[t]{3}{*}{ Cluster } & \multirow{3}{*}{$\mathbf{T}:$} & \multicolumn{6}{|c|}{ Ailsa Craig } & \multirow{3}{*}{$\begin{array}{l}\text { Mean dif- } \\
\text { ference } \\
+v \text { and }-v\end{array}$} \\
\hline & & \multicolumn{2}{|c|}{$c$} & \multicolumn{2}{|c|}{$a$} & \multicolumn{2}{|c|}{$b$} & \\
\hline & & $-\mathbf{v}$ & $+v$ & $-\mathrm{v}$ & $+v$ & $-v$ & $+v$ & \\
\hline 1 & & 121 & 123 & 117 & 118 & 119 & 121 & 2 \\
\hline 2 & & 145 & 186 & 142 & 164 & 140 & 165 & 30 \\
\hline \multirow[t]{4}{*}{3} & & 129 & 187 & 113 & 185 & 125 & 166 & 57 \\
\hline & & & & \multicolumn{4}{|c|}{ Tuckqueen } & \\
\hline & \multirow[t]{2}{*}{$\mathrm{T}:$} & \multicolumn{2}{|c|}{$c$} & \multicolumn{2}{|c|}{$a$} & \multicolumn{2}{|c|}{$b$} & \\
\hline & & $-v$ & $+v$ & $-v$ & $+v$ & $-v$ & $+v$ & $+v$ and $-v$ \\
\hline 1 & & 89 & 121 & 82 & 110 & 89 & 116 & 29 \\
\hline 2 & & 126 & 177 & 127 & 168 & 127 & 169 & 44 \\
\hline 3 & & 102 & 199 & 106 & 176 & 110 & 171 & 76 \\
\hline
\end{tabular}

Mean difference of all clusters beiween $+v$ and $-v$ in treatment $(T) c: 46$, $a: 39$ and $b: 31$.

The third cluster of the cultivar Ailsa Craig shows the same number of seeds for $+\mathrm{v}$ in treatments $c$ and $a$, and a smaller number in treatment $b$. This means that the number of seeds corresponding with $100 \mathrm{~g}$ of fruit is smaller in treatment $b$ than in treatments $c$ and $a$. If the effects of heavy pollination in treatments $c, a$ and $b$ were comparable, the conclusion is a larger mean fruit weight in $b$ than in $c$ and $a$ (see TABLE 6). In the cultivar Tuckqueen this difference in number of seeds is fourd between treatments $c$ and $a$, corresponding with the fact that $a$ and $b$ have heavier fruits in the third cluster than in the control (see TABLE 6).

\section{Discussion}

In the tomato plant, leaf, cluster and fruit growth occur simultaneously. Between leaf growth and fruit growth a balance exists, depending largely on the possibility to assimilate abundantly (VERKERK, 1955). If circumstances are favourable, as they are in glasshouses during summer in the Netherlands, a plant with relatively small leaf number can produce a heavy yield, if the soil is in good condition too. Never. theless the fruit growth may be influenced by extra pollination and special ways of pruning as has been demonstrated in the present experiment.

For normal fruit growth, pollination, followed by seed set, is needed. Auxins are activating the tissue. Materials, necessary for fruit growth are transported to the activated tissue. The better the pollination and consequently the seed set, the stronger the power of the growing fruits to accumulate food, made in the leaves, and the faster the fruit growth. On one hand this activating power is necessary, on the other hand the food materials, mostly assimilates from the leaves, are needed (VERKERK, 1957). 
The retarding effect of extra leaves on the earliness of the harvest and the increasing effect on total yield were shown in FIG. 1 for the first three clusters together and in TABLE 4 for each cluster separately. This reversal effect of more leaves in comparison to less leaves resembles the effect of lower in comparison to higher temperature. VERKERK (1955) found a correlation of $+0,90$ between mean temperature and earliness of yield and one of $-0,98$ between temperature and total yield of five clusters. This means, the lower the temperature the later the picking starts, but the higher total yield. This is exactly what was found here for the effect of more in comparison to less leaves per cluster. At a relatively high temperature many assimilates will be used for fast vegetative growth, respiration and transpiration. The assimilates for fruit growth are scarce, fruits ripen earlier after having collected less material and consequently they stay smaller than at a relatively low temperature in which case less assimilates are used for vegetative growth and also less energy is required for respiration and transpiration. In the last case the fruits can find plenty of material, grow on during a longer time and will be larger. Treatment $c$, with a relatively small amount of leaves and a relative shortness in assimilates will show the same effect in comparison to treatments $a$ and $b$ with more leaves as a higher to a lower temperature. This is exactly what was found.

To show the effect of $12 \%$ extra leaves, a heavy pollination is not necessary, - $v$ and $+v$ show approximately the same effect (FIG. 1). To show the effect of many extra leaves ( $89 \%)$, a heavy pollination is needed, however, and even then the extra yield is much less than the extra leaf number.

The earliest and highest yield was achieved by the five clusters of the control $c$. In the control there is a regular alternation of leaves and clusters and the smallest number of leaves to the cluster. In treatment $a$ there are more leaves to the cluster and this is true also for treatment $b$, especially with regard to the third cluster. Less leaves to a cluster means more flowers and also more developing seeds to a leaf. The more developing seeds and the closer they are to the leaves, the more fruit weight will be formed. This is shown by the fact that not all the extra leaves of treatment $b$ are used so intensively as those in treatment $a$. Also the more developing seeds to the leaf, the less fruit weight per seed will be formed and the earlier the fruit will be ripe. The larger the distance between the cluster and the leaves, the less the leaves are used to feed the cluster. Probably the delaying effect of the extra leaves on yield will show the same trend: the greater the distance between extra leaf and cluster, the less its delaying effect on yield.

TABLE 7 showed that more seeds are needed to get fruits of $100 \mathrm{~g}$ after heavy pollination than after natural pollination and more seeds in higher than in lower clusters. The more extra leaves, however, the less extra seeds are needed. These results are understandable in the light of what was found earlier (VERKERK, 1957). The fruit weight divided by the number of seeds, i.e. the fruit weight per seed. decreases with the number of seeds developing on the plant. This is a question of competition for the assimilates required for fruit growth. With heavy pollination many more seeds are developing on the plant, consequently the fruit weight per seed is less, so that more seeds are needed to get fruits of $100 \mathrm{~g}$. This may be the explanation for the increasing differences between $+v$ and $-v$ at higher clusters. On the other hand the problem of the assimilates is less urgent when there are more leaves. 
Anonymus

BorowiCZ-KePKOWA, A.

Cooper, A. J.

CotTrell-Dormer, W.

GIBSON, W. B.

HAN, L. H., and

K. VERKERK

HAWTHORN, L. R.

HEMPHILL, D. D., and

A. E. MurneEK

HoMÈs, M. V.,

J. R. AnsiauX and

A. Ringoet

Kerr, E, A.

$\longrightarrow$, and L. Kribs

LAMm, R.

RozGoN, K. N.

Thompson, H. C.

VERKERK, K.

SIEK

WELLENSIEK, S. J.

Woods, J. J.

\section{REFERENCES}

1950 Toppen van tomaten. Proefst. Groent. Fruitt. Glas te Naaldwijk, Jversl. 1950. 31.

1960 Tomaten met extra stengels. Proefst. Groent. Fruitt. Glas te Naaldwijk, Jversl. 1960. 83.

1937 Comparison of heading and disbudding on growth and fruiting of tomatoes. Ann. Sci. hort., Warsaw. 4, 136-152.

1960 The effect of plant form and planting density on glasshouse tomato cropping. J. hort. Sci. 35, 103-109.

1945 An electric pollinator for tomatoes. Queensl. J. Agr. Sci. 2, 157-169.

1959 Flower setting and fruit yield of tomatoes in glasshouses. Res. Exp. Rec. Minist. Agric. Belfast. 9, 97-105.

1953 Vergelijking van verschillende methoden van kunstmatige bestuiving bij tomaten. Meded. Dir. Tuinbouw. 16, 229-238.

1940 Pruning unstaked tomatoes. Proc. Amer. Soc. hort. Sci. 37, $930-934$.

1948 A preliminary study of the effect of axillary foliage on yields of tomatoes. Proc. Amer. Soc. hort. Sci. 51, 359-361.

1950 Croissance et production des fruits chez la tomate en rapport avec la taille. Trav. Centre Et. Rech. Aquicult. 3, 89114.

$1949 / 50$ Effect of extra foliage on greenhouse tomato production. Rep. Vineland hort. Exp. Stat. Ontario for 1949 and 1950. $28-29$.

1955 Electric vibrators as an aid in greenhouse tomato production. Agr. Inst. Rev. I0, 34.

1956 Avstảnds- och beskärningsförsök med drivtomat 1951-1953. Meddelande frạn Statens Trädgärdsförsök nr 100, 1-15.

1935 Methods of cultivation and care as affecting tomato yields. Proc. agr. Inst. Krasnodar. 3, 139-145.

1934 Pruning and training tomatoes. Bull. Cornell agr. Exp. Stat. No. $580,1-14$.

1955 Temperature, light and the tomato. Meded. Landb.hogesch. Wageningen. 55, 175-224.

1957 The pollination of tomatoes. Neth. J. agric. Sci. 5, 37-54.

1950 De invloed van kunstmatige bestuiving en belichting bij tomaten. Meded. Dir. Tuinbouw. 13, 620-628.

1948 Een kunstmatige bloembestuiver. Meded. Dir. Tuinbouw. 11, $101-104$.

1938 Pruning staked tomatoes. Sci. Agric. 18, 620-626. 